\title{
Positive impact of IGF-I-coupled nanoparticles on the differentiation potential of human chondrocytes cultured on collagen scaffolds
}

This article was published in the following Dove Press journal:

International Journal of Nanomedicine

4 February 2015

Number of times this article has been viewed

\author{
Juliane Pasold' \\ Kathleen Zander ${ }^{1}$ \\ Benjamin Heskamp' \\ Cordula Grüttner ${ }^{2}$ \\ Frank Lüthen ${ }^{3}$ \\ Thomas Tischer' \\ Anika Jonitz-Heincke' \\ Rainer Bader ${ }^{\prime}$ \\ 'Department of Orthopaedics, \\ Biomechanics and Implant Technology \\ Laboratory, University Medicine \\ Rostock, Rostock, Germany; \\ ${ }^{2}$ Micromod Particletechnology $\mathrm{GmbH}$, \\ Rostock, Germany; ${ }^{3}$ Institute of Cell \\ Biology, University Medicine Rostock, \\ Rostock, Germany
}

Purpose: In the present study, silica nanoparticles (sNP) coupled with insulin-like growth factor 1 (IGF-1) were loaded on a collagen-based scaffold intended for cartilage repair, and the influence on the viability, proliferation, and differentiation potential of human primary articular chondrocytes was examined.

Methods: Human chondrocytes were isolated from the hyaline cartilage of patients $(n=4$, female, mean age: $73 \pm 5.1$ years) undergoing primary total knee joint replacement. Cells were dedifferentiated and then cultivated on a bioresorbable collagen matrix supplemented with fluorescent sNP coupled with IGF-1 (sNP-IGF-1). After 3, 7, and 14 days of cultivation, cell viability and integrity into the collagen scaffold as well as metabolic cell activity and synthesis rate of matrix proteins (collagen type I and II) were analyzed.

Results: The number of vital cells increased over 14 days of cultivation, and the cells were able to infiltrate the collagen matrix (up to $120 \mu \mathrm{m}$ by day 7). Chondrocytes cultured on the collagen scaffold supplemented with SNP-IGF-1 showed an increase in metabolic activity (5.98-fold), and reduced collagen type I (1.58-fold), but significantly increased collagen type II expression levels ( 1.53 -fold; $P=0.02)$ after 7 days of cultivation compared to 3 days. In contrast, chondrocytes grown in a monolayer on plastic supplemented with SNP-IGF-1 had significantly lower metabolic activity (1.32-fold; $P=0.007)$, a consistent amount of collagen type I, and significantly reduced collagen type II protein expression ( 1.86 -fold; $P=0.001)$ after 7 days compared to 3 days.

Conclusion: Collagen-based scaffolds enriched with growth factors, such as IGF-1 coupled to nanoparticles, represent an improved therapeutic intervention for the targeted and controlled treatment of articular cartilage lesions.

Keywords: chondrogenic differentiation, silica nanoparticles, growth factor, 3D-matrix, cartilage repair

\section{Introduction}

Articular hyaline cartilage is a unique connective tissue that has to withstand high physiological mechanical loading. However, once the cartilage development is completed, mature chondrocytes no longer proliferate, meaning that there is almost no intrinsic regenerative potential. Therefore, during the normal aging process, robust articular cartilage is slowly but continuously degraded. ${ }^{1}$ Additionally, genetic and age-related cartilage degradation, like osteoarthritis, as well as trauma-induced cartilage lesions occur and are major challenges for medical therapeutic approaches in an aging society. There are many research groups dealing with the question of how chondrogenic defects of varying degrees could be best treated. The main goal is to rebuild hyaline cartilage and thus induce and improve the self-healing process. ${ }^{2}$
Correspondence: Juliane Pasold Department of Orthopaedics, Biomechanics and Implant Technology Laboratory, University Medicine Rostock, Doberaner Strasse I42, 18057 Rostock, Germany

Tel +493814949306

Fax +49 38I 4949308

Email juliane.pasold@med.uni-rostock.de
International Journal of Nanomedicine 20|5: | 0 | |3 |-| | 43 
By slowing down the progression of cartilage degradation, the use of a total knee endoprosthesis could be delayed or even prevented. ${ }^{3}$ Recent in vitro studies indicate that the most efficient chondrogenic differentiation of chondrocyte-like progenitor cells and mesenchymal stem cells is achieved by using standard cell culture medium supplemented with growth factors like insulin-like growth factor (IGF) 1 , transforming growth factor (TGF) $\beta 1$ and 2, fibroblast growth factor (FGF) 2, and bone morphogenetic protein (BMP) 2. ${ }^{4-6}$ It is known that IGF-1 enhances the synthesis of proteoglycans and directly decreases the degradation of proteoglycans in cartilage. ${ }^{7}$ Moreover, it was shown that IGF-1 helps to maintain the survival of chondrocytes. ${ }^{8}$ In combination with TGF $\beta$, IGF-1 has a stimulatory effect on the adhesion of chondrocytes to fibronectin and collagen type II. ${ }^{9}$ It is important to ensure the controlled delivery of biomolecules, like IGF-1, to avoid adverse effects. Nano-sized carriers (nanoparticles) are considered an attractive tool for this, as nanoparticles are small in dimension, offer a high surface area to volume ratio, and enable targeted drug delivery. ${ }^{10,11}$ Within the last 20 years, in biomedical research, mesoporous silica nanoparticles (sNP) have been increasingly developed as suitable vehicles for controlled drug delivery in clinical applications and diagnostics. Those functional nanocarriers need to fulfill important characteristics, for example high biocompatibility; stability and easy internalization; high traceability and imaging capacity; low toxicity; and controlled drug delivery. ${ }^{12}$ For the study of receptor-ligand interactions, stimulating biomolecules can also be attached to the surface of sNP. This enables an increased and targeted cell stimulation tool which allows the binding capacity to be visualized through fluorescently labeled nanoparticles. ${ }^{13}$ The nanoparticle-IGF-1 conjugates used in this work have a relevant advantage compared to mesoporous particles loaded with growth factors. From the latter, the growth factor is released and diffuses through the collagen matrix and thus distributes all over, while for the nanoparticles, the growth factor is immobilized by chemical bonding to the particles and thus remains in the collagen matrix at the destination.

With regard to the clinical application for cartilage repair, cells have been incubated in three-dimensional culture systems, like pellets and microspheres, ${ }^{4,14}$ as well as hydrogels or biomaterials. ${ }^{15-18}$ Superficial cartilage defects have mainly been treated with hyaluronic acid (HA), while chondral and osteochondral lesions have been medicated by means of HA and autologous cartilage transplantation (ACT) since 1994. ${ }^{19-23}$ In the latter case, the use of matrixassisted autologous chondrocyte transplantation has become increasingly attractive since 1998 , because articular cartilage defects of varying degrees can be replenished more easily and in a more targeted manner. ${ }^{22,24}$ So far, a variety of different synthetic and natural materials have been investigated with respect to cartilage repair. ${ }^{3,25}$ The main focus lies on restoring the complex structure and properties of hyaline cartilage to achieve long-term improvements in cartilage engineering. ${ }^{26}$ Despite a high number of studies, the optimal scaffold for the repair of cartilage defects has not yet been identified. There are a lot of requirements that need to be fulfilled. The material has to be biocompatible, biodegradable, and bioactive. $^{3}$ Cells are expected to grow into the scaffold and start producing their own extracellular matrix, so that the defect is replenished with autologous chondrocytes and a functional hyaline cartilage-like matrix at the end. ${ }^{27}$ Collagen-based biomaterials turned out to be well-suited; for example, scaffolds consisting of collagen type I in combination with collagen type II and HA were shown to positively influence cell attachment, migration, and proliferation as well as chondrogenic differentiation. ${ }^{25}$ The reason for this is the nanoscale fibrous structure (50-500 $\mathrm{nm}$ in diameter) offering binding sites that are comparable to the native matrix in vivo. ${ }^{28}$

In the present in vitro study, a bioresorbable collagen scaffold that was clinically used for the surgical filling of articular cartilage defects was enriched with IGF-1, in suspension or attached to nanoparticles, to compare which route of administration has a greater impact on the regenerative potential of chondrocytes. We hypothesized that cell viability, proliferation, and production of the extracellular matrix will be increased by the addition of IGF-1 administered in the form of sNP.

\section{Materials and methods Conjugation of IGF-I on the surface of fluorescent silica nanoparticles}

Red fluorescent silica nanoparticles ( sicastar $^{\circledR}$-redF, 40-01103; micromod Partikeltechnologie GmbH, Rostock, Germany) with a diameter of $1 \mu \mathrm{m}$ and amino groups on the surface (Figure 1A) were applied for the conjugation of IGF-1. These nanoparticles were prepared by a modified Stöber process including the covalent binding of fluorescent dye within the whole particle matrix. ${ }^{29}$ The conjugation strategy of IGF-1 on the surface of the fluorescent silica nanoparticles (sNP) is based on the introduction of maleimide groups on the surface of amino-functionalized nanoparticles via a polyethylene glycol (PEG)24 spacer. In the second step, the maleimide-functionalized nano particles react with the thiolated IGF-1 to form a stable chemical bond between IGF-1 and particles. ${ }^{30}$ Therefore, $250 \mu \mathrm{L}$ of $\operatorname{sicastar}^{\circledR}-\mathrm{redF}(50 \mathrm{mg} / \mathrm{mL})$ was suspended in 
phosphate-buffered saline (PBS) buffer ( $\mathrm{pH}=7.4,0.05 \mathrm{M}$ ethylenediaminetetraacetic acid [EDTA]) and mixed with $8 \mu \mathrm{L}$ of $125 \mathrm{mM} \mathrm{N}$-hydroxysuccinimide-PEG24-maleimide solution in dimethyl sulfoxide (SM (PEG) ${ }_{24}$ amine-tosulfhydryl crosslinkers with soluble PEG spacer arms; Thermo Fisher Scientific, Waltham, MA, USA). After shaking the suspension for 2 hours at room temperature, the particles were washed twice with PBS buffer $(\mathrm{pH}=7.4$, $0.05 \mathrm{M}$ EDTA) and centrifuged at 3,000 rpm for 10 minutes. Then, $1 \mathrm{~mL}$ of IGF-1 solution in PBS buffer $(\mathrm{pH}=7.4,0.05$ M EDTA) with a concentration of $50 \mu \mathrm{g} / \mathrm{mL}$ was incubated with $13 \mu \mathrm{L}$ of a $1.4 \mathrm{mM}$ solution of 2-iminothiolane in water
(Thermo Fisher Scientific) for 1 hour at room temperature. The thiolated IGF-1 was purified by washing with a G-25 desalting column (GE Healthcare Europe GmbH, Freiburg, Germany) and transferred to the maleimide-functionalized particles. After shaking for 2 hours at room temperature, $100 \mu \mathrm{L}$ of $20 \mathrm{mM}$ cysteine solution in water was added to block the unreacted maleimide groups. Finally, the particles were washed twice with PBS buffer $(\mathrm{pH}=7.4,0.05 \mathrm{M}$ EDTA) by centrifugation at 3,000 rpm for 10 minutes to give $500 \mu \mathrm{L}$ of particle suspension with a concentration of $25 \mathrm{mg} / \mathrm{mL}$. A hydrodynamic diameter of $1,059 \mathrm{~nm}$ of the IGF-1-conjugated particles was measured by photon

A

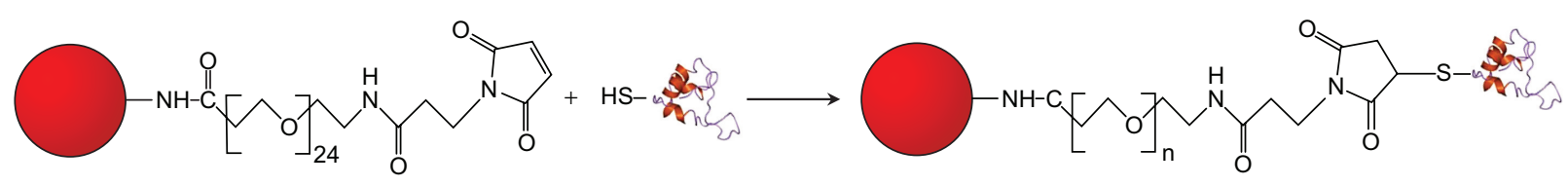

B

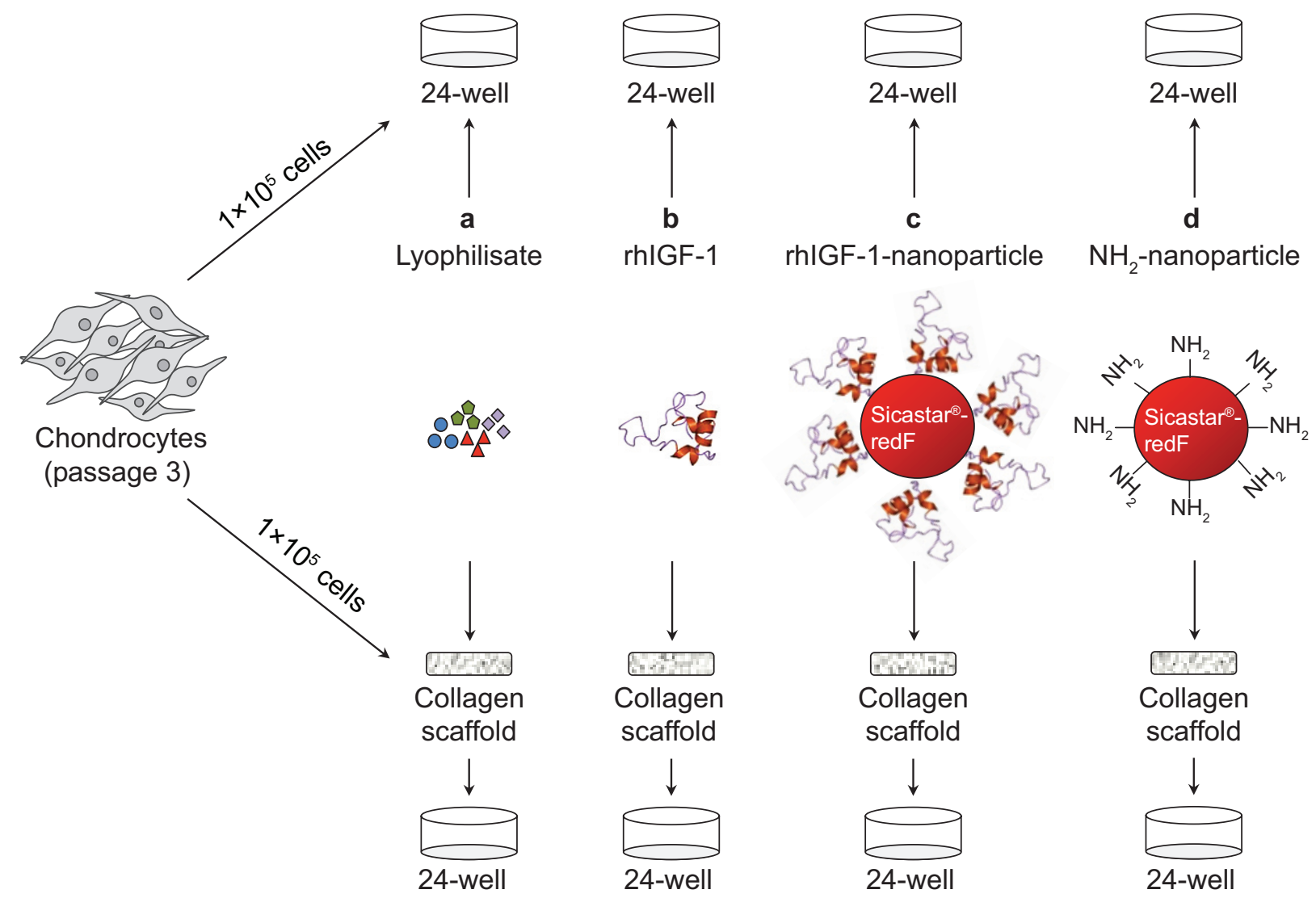

Figure I Chemical synthesis of IGF-I nanoparticles and application for in vitro cultivation of dedifferentiated chondrocytes.

Notes: (A) Conjugation of the thiolated IGF-I to PEG24-maleimide functionalized red fluorescent silica nanoparticles (sicastar ${ }^{\circledR}$-redF). (B) In passage three, chondrocytes were seeded either on plastic (2-D; upper panel) or on a collagen scaffold (3-D; lower panel) with a concentration of $\mathrm{I} \times \mathrm{I} 0^{5} \mathrm{cells}$ per I $\mathrm{cm}^{2}$. Cells were incubated with (a)

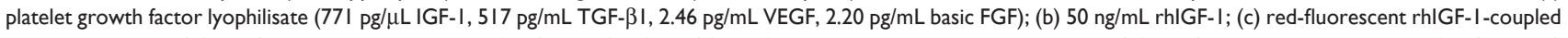
silica nanoparticles $(12.5 \mu \mathrm{g} / \mathrm{mL}$ particle suspension $=50 \mathrm{ng} / \mathrm{mL}$ rhIGF-I); or (d) red-fluorescent control silica nanoparticles $(I 2.5 \mu \mathrm{g} / \mathrm{mL}$ particle suspension $=50 \mathrm{ng} / \mathrm{mL} \mathrm{NH}$ ) for 48 and 96 hours, as well as for 3, 7, and 14 days. The supplements (lyophilisate, rhIGF-I, nanoparticles) were only added in the beginning, when the cells were seeded. During cultivation over 14 days, medium (without supplements) was changed every 2-3 days.

Abbreviations: IGF-I, insulin-like growth factor I; TGF- $\beta$ I, transforming growth factor beta I; VEGF, vascular endothelial growth factor; FGF, fibroblast growth factor; rhIGF-I, recombinant human IGF-I. 
correlation spectroscopy (Zetasizer Nano-ZS90; Malvern Instruments, Malvern, UK).

\section{Cell culture}

Primary chondrocytes were isolated from the hyaline cartilage of patients ( $n=4$, female, mean age: $73 \pm 5.1$ years) undergoing primary total knee joint replacement after patient consent had been obtained. The study was approved by the Local Ethical Committee (registration number: A2009-17).

The cartilage was removed from the underlying bone, cut into small pieces, and washed three times in PBS (PAA Laboratories, Cölbe, Germany). Afterwards, the cartilage ( $\sim 3$ $\mathrm{g} \mathrm{w} / \mathrm{w}$ ) was treated with $1 \%$ Gibco $^{\circledR}$ trypsin/EDTA (Thermo Fisher Scientific) for 20 minutes at $37^{\circ} \mathrm{C}$ followed by $0.2 \%$ collagenase A (Hoffman-La Roche Ltd., Basel, Switzerland) in Dulbecco's Modified Eagle's Medium (DMEM) supplemented with $10 \%$ fetal calf serum, $1 \%$ amphotericin $\mathrm{B}$, and $1 \%$ Gibco $^{\circledR}$ penicillin/streptomycin (Thermo Fisher Scientific) at $37^{\circ} \mathrm{C}$ overnight. The cell suspension was filtered through a cell strainer (pore size, $70 \mu \mathrm{m}$; Nunc, Wiesbaden, Germany) and centrifuged at $118 \times g$ for 10 minutes. The cell pellet was resuspended in DMEM with the supplements mentioned before and with ascorbic acid ( $50 \mu \mathrm{g} / \mathrm{mL}$; Sigma-Aldrich Co., St Louis, MO, USA). Cells were seeded in a $25-\mathrm{cm}^{2}$ culture flask and incubated in a humidified atmosphere at $37^{\circ} \mathrm{C}$ and $5 \% \mathrm{CO}_{2}$. The medium was changed every $2-3$ days. After reaching $90 \%$ confluence $\left(\sim 5 \times 10^{5}\right.$ cells $/ 25-\mathrm{cm}^{2}$ flask $)$, the cells were trypsinized and split at a ratio of 1 to 6 . For all experiments, cryoconserved chondrocytes were used. After thawing, cells were centrifuged at $118 \times g$ for 10 minutes, transferred into $75-\mathrm{cm}^{2}$ flasks (passage two), and incubated in a humidified atmosphere at $37^{\circ} \mathrm{C}$ and $5 \% \mathrm{CO}_{2}$.

In passage three, $1 \times 10^{5}$ dedifferentiated cells (per $1 \mathrm{~cm}^{2}$ or 24-well format) were either transferred onto a bioresorbable, collagen-based, two-layer matrix (three-dimensional) supplemented with sodium hyaluronate (MBP, NeustadtGlewe, Germany) or grown in a monolayer on plastic (two-dimensional), which served as controls. As shown in Figure 1, the cells were incubated with: a) platelet growth factor lyophilisate containing $771 \mathrm{pg} / \mu \mathrm{L}$ IGF-1, $517 \mathrm{pg} / \mathrm{mL}$ TGF- $\beta 1,2.46 \mathrm{pg} / \mathrm{mL}$ VEGF (vascular endothelial growth factor), and $2.20 \mathrm{pg} / \mathrm{mL}$ basic FGF (DOT, Rostock, Germany); b) recombinant human IGF-1 (rhIGF-1) (R\&D Systems, Inc., Minneapolis, MN, USA); c) red-fluorescent (569-585 nm) rhIGF-1-coupled sNP (4 $\mu \mathrm{g}$ rhIGF-1 per $1 \mathrm{mg}$ particle); or d) control $\mathrm{NH}_{2}$-nanoparticles sNP ( sicastar $^{\circledR}$-redF [micromod Partikeltechnologie $\left.\mathrm{GmbH}\right]$ ) for
3, 7, and 14 days. The supplements (lyophilisate, rhIGF-1, sNPs) were only added at the time of cell seeding. The first medium change was conducted after 3 days. All particles which were not bound until then were washed away. During the course of further cultivation, the medium was changed every $2-3$ days in long-term cultivation. During short-term cultivation over 4 days, serum-free chondrogenic medium (DMEM containing ascorbic acid [50 $\mu \mathrm{g} / \mathrm{mL}]$ ), dexamethasone (100 nM; Sigma-Aldrich Co.), and ITS ${ }^{\mathrm{TM}}$ (complete medium to ITS ${ }^{\text {TM }}$ in a 100:1 ratio [BD, Franklin Lakes, NJ, USA]) were used and no medium changes were conducted.

\section{DNA isolation and quantification}

Proteinase K, DNA lysis buffer, and RNase A were added to cells grown in a monolayer and to cells grown on collagen scaffolds. After 1 hour of incubation at $50^{\circ} \mathrm{C}$ with continuous shaking, biomaterial residues were transferred into $2-\mathrm{mL}$ homogenization tubes containing small steel beads (Precellys Steel kit, 2.8 mm; PeqLab Biotechnologie GmbH, Erlangen, Germany), covered with $100 \mu \mathrm{L}$ Tris-EDTA-buffer, and homogenized for 30 seconds at $5,000 \times g$. DNA isolation was performed using the peqGOLD Tissue DNA mini kit (PeqLab Biotechnologie $\mathrm{GmbH}$ ) according to the manufacturer's instructions. Afterwards, DNA concentrations were measured with the Qubit Fluorometer according to the instructions of the manufacturer (Thermo Fisher Scientific).

\section{Cell biological tests}

The metabolic cell activity was determined with the colorimetric water-soluble-tetrazolium salt (WST-1) assay (Hoffman-La Roche Ltd.). After incubation with a mix of WST assay reagent and cell culture medium at a ratio of 1 to 10 for 60 minutes at $37^{\circ} \mathrm{C}$, the optical density (OD) was measured at $450 \mathrm{~nm}$ (reference: $630 \mathrm{~nm}$ ) using an Opsys MR microplate reader (Dynex Technologies, Denkendorf, Germany). The cell viability was assessed using a LIVE/DEAD ${ }^{\mathcal{O}}$ assay kit (Thermo Fisher Scientific). The two-color assay discriminates vital from dead cells by simultaneously staining with green-fluorescent (494-517 nm) calcein-acetoxymethyl (calcein-AM) to indicate intracellular esterase activity, and red-fluorescent $(528-617 \mathrm{~nm}$ ) ethidium homodimer-1 to predict the loss of plasma membrane integrity. The assay was performed as recommended by the manufacturer. Images of the cells were taken with a fluorescence microscope (Nikon Type 120; Nikon Corporation, Tokyo, Japan) and evaluated with NIS-Elements software (Nikon Corporation). Furthermore, scanning electron microscopy (SEM) with the DSM 960 A (Carl Zeiss Meditec AG, Jena, 
Germany) and confocal laser scanning microscopy (LSM) using the LSM 780 (Carl Zeiss Meditec AG) were conducted to evaluate the surface structure of the collagen scaffold, the cell integrity into the scaffold, and the uptake of nanoparticles by the cells. The three-dimensional reconstruction of z-stack recordings was performed using ZEN Imaging Software (Black edition 2012, Version 2.0).

\section{Procollagen type I (C-terminal of type I collagen) and type II (carboxy propeptide of type II collagen) quantification}

Synthesis rates of procollagen types I and II were determined by enzyme-linked immunosorbent assay (ELISA) (TECOmedical, Sissach, Switzerland). The amount of propeptides, in this case the $\mathrm{C}$-terminal of type I collagen (CICP) and the carboxy propeptide of type II collagen (CPII), provides a stoichiometric representation of the production of collagen types I and II, respectively, because CICP and CPII are cleaved from mature collagen molecules prior to incorporation into growing collagen fibrils. Hence, supernatants of cells grown in a monolayer and on the collagen scaffold were collected (after 2, 3, 4, and 7 days of cultivation) and stored at $-20^{\circ} \mathrm{C}$. The assays were performed according to the manufacturer's instructions. Absorbance was measured at $450 \mathrm{~nm}$ for the CPII ELISA and $405 \mathrm{~nm}$ for the CICP ELISA using Opsys MR $^{\mathrm{TM}}$ microplate reader (Dynex Technologies).

\section{Statistics}

Means and standard deviations were calculated for each group $(n \geq 3)$ and compared to each other. Additionally, we analyzed time-dependent gradients within each group. Statistical analysis was evaluated by analysis of variance post hoc-least significant difference using IBM ${ }^{\circledR}$ SPSS $^{\circledR}$ Statistics Version 20 (IBM Corporation, Armonk, NY, USA). A $P$-value $<0.05$ was considered statistically significant.

\section{Results \\ Characterization of chondrocyte growth on the collagen scaffold}

The collagen-based scaffold was initially present in a dried form and was therefore incubated in cell culture medium for at least 30 minutes $\left(37^{\circ} \mathrm{C}, 5 \% \mathrm{CO}_{2}\right)$ to be enriched with medium before cells were added. The scaffold was examined using a scanning electron microscope to get an impression of how the surface structure changes during an incubation time of 7 days with medium. The surface topography appeared
A

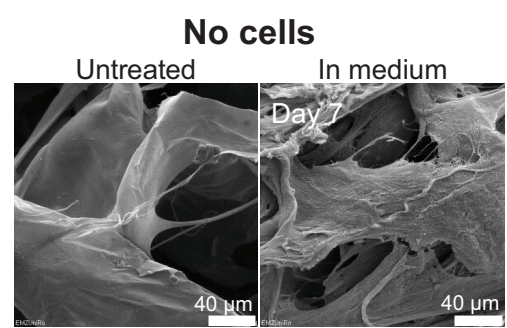

With cells

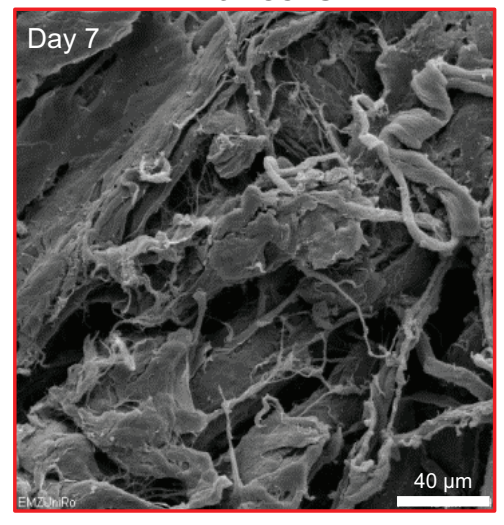

B
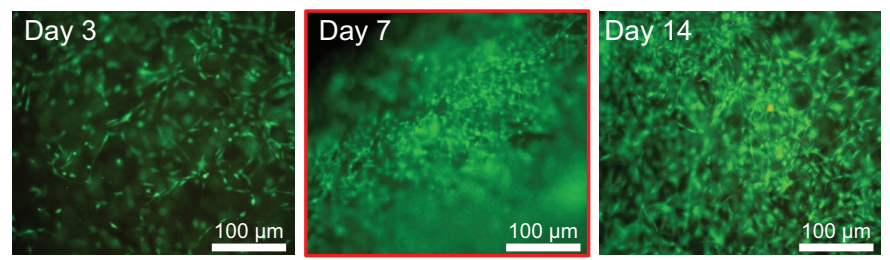

C

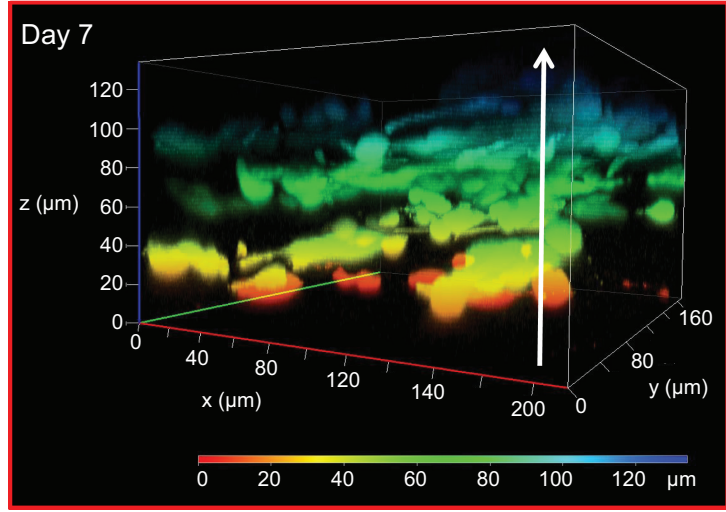

Figure 2 In vitro characterization of chondrocytes growth on the collagen-based scaffold.

Notes: (A) Representative SEM pictures of the scaffold: untreated and dried (upper left); incubated in DMEM supplemented with I0\% FCS, I\% penicillin/streptomycin, and I\% amphotericin B for 7 days (upper right); and incubated with chondrocytes for 7 days (lower picture). (B) Fluorescence microscopy of live/dead stained chondrocytes grown on the collagen scaffold for 3, 7, and I 4 days (vital cells = green; dead cells = red). (C) Confocal microscopy (z-stack) of 7-day-old chondrocytes infiltrating the scaffold up to $120 \mu \mathrm{m}$.

Abbreviations: DMEM, Dulbecco's Modified Eagle's Medium; FCS, fetal calf serum; SEM, scanning electron microscopy. 
slightly frayed and loosened up, but the scaffold remained intact and chondrocyte-like cells isolated from human articular cartilage could easily attach (Figure 2A). In Figure 2B, high cell viability and cell proliferation between days 3 and 14 of cultivation was confirmed by fluorescence microscopy. Additionally, a z-stack, recorded with LSM, indicated that the cells not only grow at the surface, but infiltrate the collagen scaffold. Viable cells could be detected within the collagen scaffold at a depth of $120 \mu \mathrm{m}$ after only 7 days of cultivation (Figure 2C).

Figure 3 shows that the metabolic cell activity increases from 3 to 7 days (OD/median: 0.201 and 0.583 , respectively) and remains stable from 7 to 14 days of cultivation (OD/median: 0.583 and 0.532, respectively). Furthermore, human dedifferentiated chondrocytes grown on the collagen scaffold appeared to redifferentiate and remain stable over a longer cultivation period, which was indicated by the slightly increased production of the cartilaginous matrix compound collagen type II during cultivation over 14 days (median ratio of CPII/DNA: 826.20 [3 days]; 1,216.27 [7 days]; and 1,352.14 [14 days]).

\section{Stimulating effect of IGF-I-coupled nanoparticles on dedifferentiated cells}

Dedifferentiated human chondrocytes of passage three were seeded on cell culture plastic (monolayer) with the addition of IGF-1-coupled nanoparticles. First, cells were cultured over 4 days without conducting a medium change to look for particle binding by the cells via the IGF-1 receptor, and the fate and continuance of particles during cultivation. After 2 and 4 days, cells were washed with PBS and stained with calcein-AM, so that green fluorescent viable cells, but also red fluorescent particles, were detectable with a fluorescence microscope. Figure 4 shows viable, proliferative cells after 2 (upper panels) and 4 days (lower panels) as well as IGF-1-coupled nanoparticles bound to the cells (merged pictures). From 2 to 4 days, there was a clear increase in cell number, while the amount of particles remained the same. Subsequently, we examined the production of procollagen types I and II at day 2 and day 4 of cultivation to identify an early stimulating effect of IGF-1coupled nanoparticles (sNP-IGF-1) on the redifferentiation of passage three chondrocyte-like cells (Figure 5). After 2 days of cultivation, collagen type I was highest in the supernatant of cells cultured with sNP-Co (control nanoparticles) (median: 4,246.28 $\mathrm{ng} / \mathrm{mL}$ ) and lowest for the cells incubated with rhIGF (median: 3,271.15 ng/mL). In all three approaches, the amount of collagen type I was reduced on day 4, which was most evident for cells incubated with sNP-IGF-1 (median: 1,846.93 ng/mL) and rhIGF-1 (median: 1,259.93 ng/mL). Moreover, we could identify an early inductive effect on chondrogenic differentiation when IGF-1-coupled nanoparticles were added, as the amount of type II collagen was highest in the supernatant of cells incubated for 2 days with sNP-IGF-1 (median: $225.82 \mathrm{ng} / \mathrm{mL}$ ) in comparison to sNP-Co (median: $217.32 \mathrm{ng} / \mathrm{mL}$ ) and rhIGF-1 (median: $124.79 \mathrm{ng} / \mathrm{mL}$ ). From days 2 to 4 of cultivation, we found increased collagen type II production, especially by chondrocytes incubated with IGF-1-coupled nanoparticles (median: $383.82 \mathrm{ng} / \mathrm{mL}$ ) in monolayer. This result points to a chondroinductive effect and a drug-effectiveness period of less than 4 days.
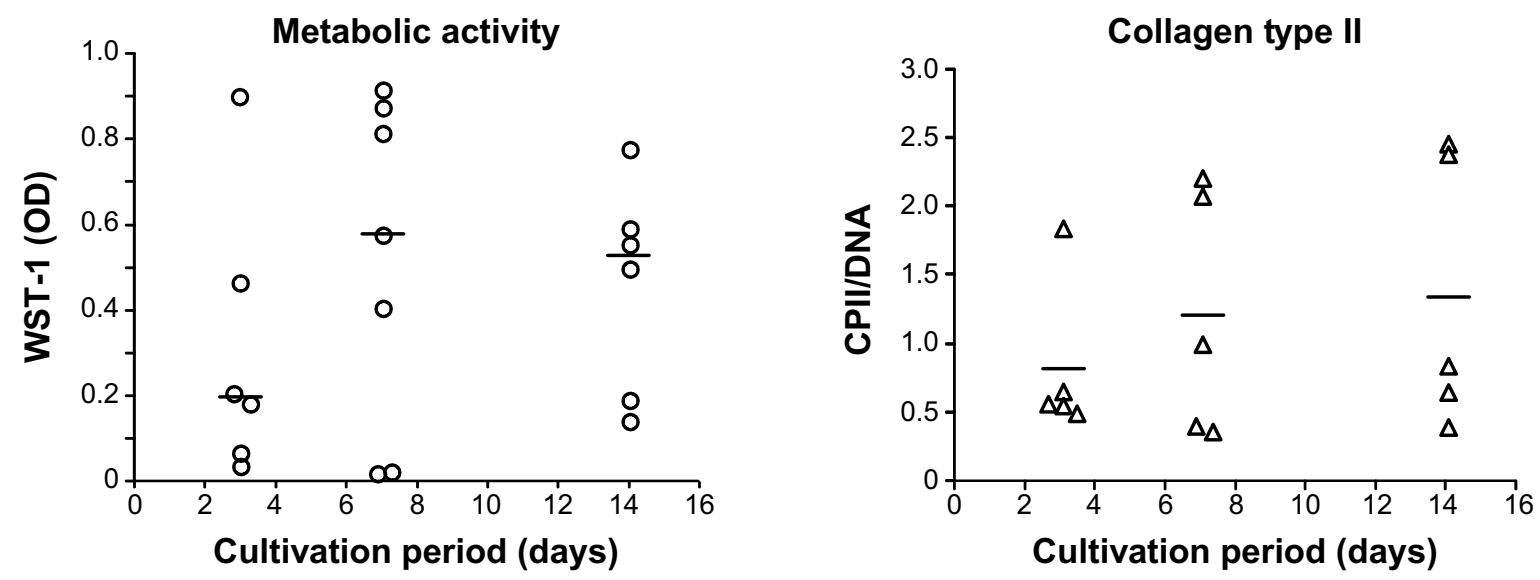

Figure 3 Metabolic cell activity and matrix production of primary chondrocytes cultured on the collagen-based scaffold.

Notes: Chondrocytes were isolated from the hyaline cartilage of patients $(\mathrm{n} \geq 5)$ undergoing primary total knee joint replacement and seeded $\left(I \times I 0^{5}\right.$ cells/cm $\left.{ }^{2}\right)$ onto the scaffold before being incubated for 3, 7, and I4 days. The metabolic activity was measured via WST-I (left panel). The production of CPII was quantified and normalized to the DNA content per patch (right panel). Each symbol (circle, triangle) represents a donor. Black lines correspond to the median. Analysis of variance post hoc-LSD was conducted (no significant differences between 3, 7, and 14 days of cultivation).

Abbreviations: CPII, procollagen type II; LSD, least significant difference; OD, optical density; WST-I, water-soluble-tetrazolium salt. 


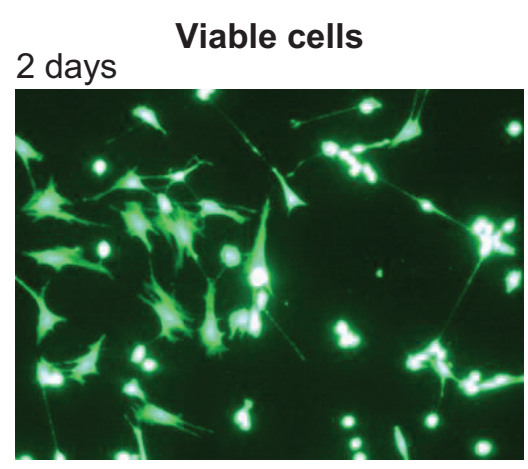

Red fluorescent particles

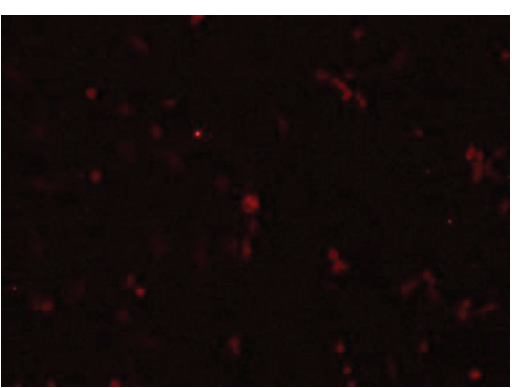

4 days

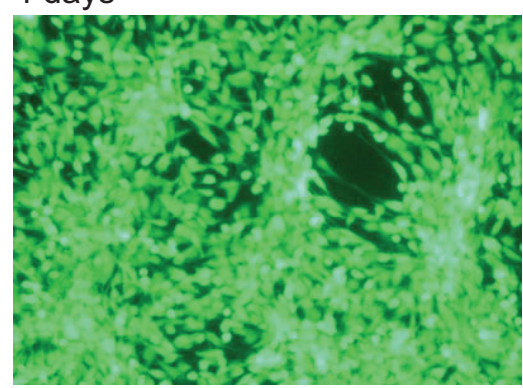

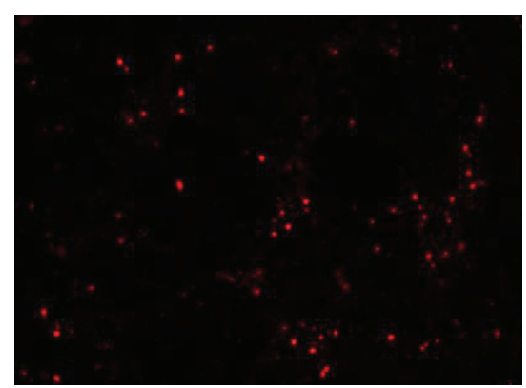

Figure 4 Binding of IGF-I-coupled nanoparticles by chondrocytes grown in a monolayer for 2 and 4 days.

Notes: Chondrocytes were isolated from the hyaline cartilage of patients $(n=3)$ undergoing primary total knee joint replacement and cultured in a monolayer ( $I \times 10^{5}$ cells per well in a 24 -well plate). Cells were suspended with medium supplemented with red-fluorescent rhIGF-I-coupled nanoparticles ( $12.5 \mu g / m L$ particle suspension $=50 \mathrm{ng} / \mathrm{mL}$ rhIGF-I). During cultivation, no medium change was conducted. After 2 and 4 days, cells were stained with calcein-AM to visualize vital cells (green, upper left and lower left) using a fluorescence microscope. The wavelength of $569-585 \mathrm{~nm}$ was used to visualize IGF-I-coupled nanoparticles (red, upper middle and lower middle). The pictures of cells and particles were combined (green, upper right and lower right; overlays). Red darts indicate particles bound by chondrocytes. White bar $=100 \mu \mathrm{m}$. Abbreviation: calcein-AM, calcein-acetoxymethyl; IGF-I, insulin-like growth factor I; rhIGF-I, recombinant human IGF-I.
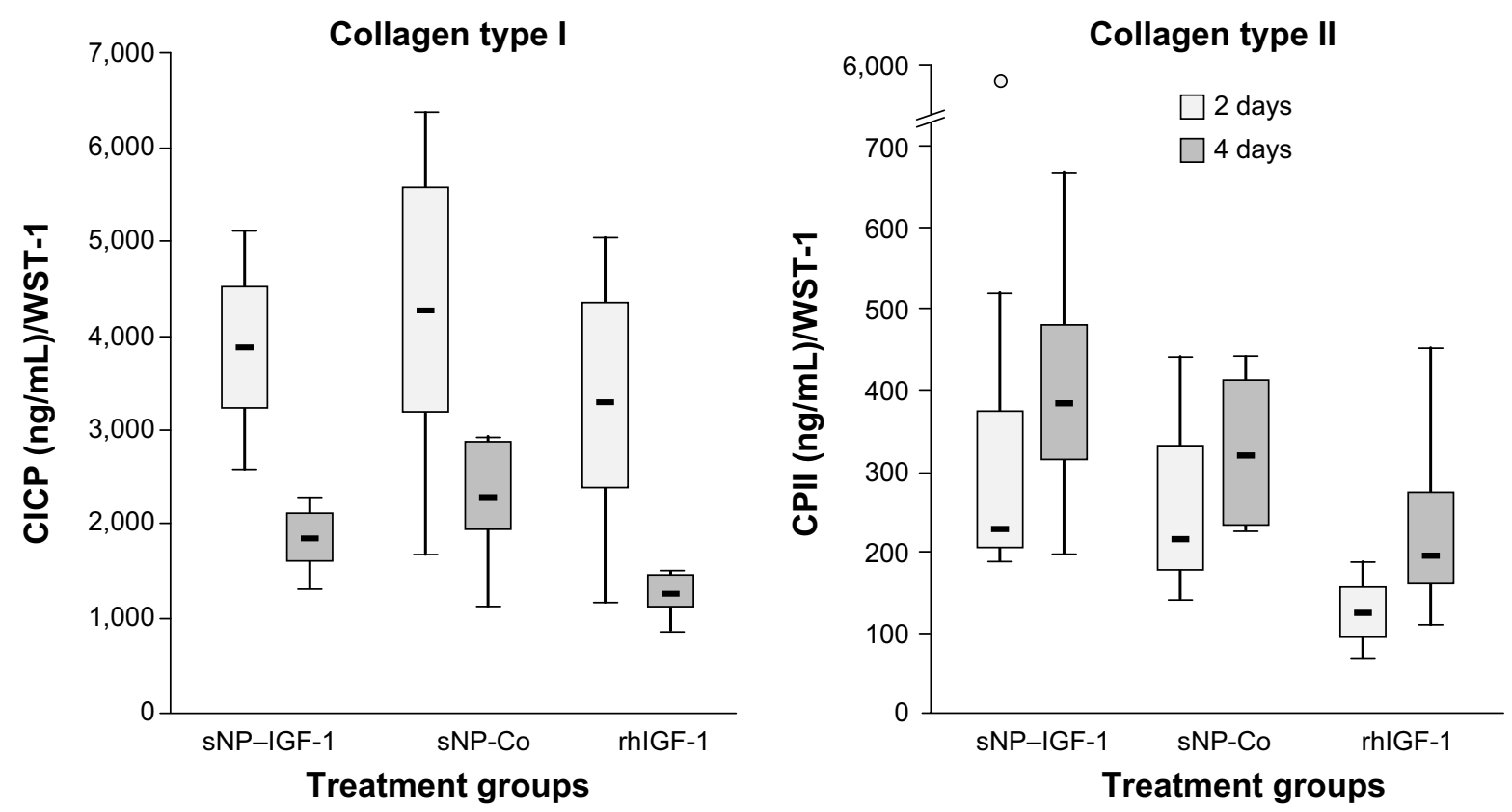

Figure 5 Effect of IGF-I-coupled nanoparticles on chondrocytes grown in a monolayer for 2 and 4 days.

Notes: Chondrocytes were isolated from the hyaline cartilage of patients $(n=3)$ undergoing primary total knee joint replacement and were cultured in a monolayer $\left(I \times I 0^{5}\right.$ cells per well in a 24-well plate). Cells were suspended in serum-free medium supplemented with rhlGF- I-coupled nanoparticles (sNP-IGF-I; I $2.5 \mu g / \mathrm{mL}$ particle suspension $=50 \mathrm{ng} / \mathrm{mL}$ rhlGF-I), control particles (sNP-Co; $12.5 \mu \mathrm{g} / \mathrm{mL}$ particle suspension $=50 \mathrm{ng} / \mathrm{mL} \mathrm{NH}_{2}$ ), and rhIGF-I (50 ng/mL). No medium change was conducted. After 2 and 4 days, CICP (osteogenic marker) as well as CPII (chondrogenic marker) were quantified in the cell supernatant by means of enzyme-linked immunosorbent assay. Data were normalized by division with WST-I absorption values. Boxes denote interquartile ranges, horizontal lines within the boxes denote medians, and whiskers denote minimum and maximum values. Analysis of variance post hoc-LSD was conducted (there were no significant differences between 2 and 4 days of incubation nor between the 3 different treatments). Abbreviations: CICP, procollagen type I; CPII, procollagen type II; LSD, least significant difference; sNP, silica nanoparticles; sNP-Co, control nanoparticles; WST-I, watersoluble-tetrazolium salt; IGF-I, insulin-like growth factor I; rhIGF-I, recombinant human IGF-I. 


\section{Impact of a collagen scaffold in combination with growth factors on chondrogenic redifferentiation}

Dedifferentiated human chondrocytes of passage three were either seeded on a collagen scaffold or on cell culture plastic with the initial addition of SNP-IGF-1, sNP-Co, rhIGF-1, or growth factor lyophilisate. After 3 and 7 days of incubation, the metabolic activity was measured and the total production of collagen types I and II was determined in all cell supernatants (Figure 6A-F).

In general, higher metabolic cell activity is detectable for cells grown in a monolayer than for cells grown on a collagen scaffold, likely due to the fact that the inner cells here may not have been adequately covered in the 1-hour incubation period of the WST-1 substance. Interestingly, the metabolic activity of cells cultured in a monolayer was significantly reduced at day 7 compared to day 3 when initially incubated with sNP-IGF-1 (1.32-fold; $P=0.007)$ and rhIGF-1 (2.91-fold; $P<0.001$ ), but significantly increased when initially incubated with lyophilisate $(1.93$-fold; $P<0.001)$. Cells grown on the collagen scaffold with the addition of sNP-IGF-1 showed a 5.96-fold increased metabolic activity after 7 days compared to after 3 days (Figure 6A and D). Interestingly, there were already significant differences in cell metabolic activity between the sNP-IGF-1-stimulated cells and the three comparison groups after 3 days of cultivation on plastic. Thus, sNP-IGF-1-loaded cells are $42.3 \%, 76.9 \%$, and $67.4 \%$ more metabolically active than cells incubated with sNP-Co, rhIGF-1, and lyophilisate, respectively (Figure 6A). At day 7 , cells incubated with rhIGF-1 had the lowest (OD [mean]: 0.341 ) activity, while those with lyophilisate had the highest (OD [mean]: 2.024) compared to cells with nanoparticles (OD [mean]: sNP-IGF-1, 1.334; sNP-Co, 1.170). Cells grown on the collagen scaffold showed a different behavior. At day 3 , the highest activity was found for rhIGF-1-(OD [mean]: 0.334 ) and lyophilisate-incubated (OD [mean]: 0.239 ) cells compared to particle-loaded cells (OD [mean]: sNP-IGF-1, 0.043; sNP-KO, 0.058). After 7 days, however, all four cell approaches had the same level of activity (Figure 6D).

It is noticeable that cells grown in monolayer produce much higher amounts of collagen type I than cells grown on the collagen scaffold. This applies after both 3 and 7 days. Compared to sNP-IGF-1-stimulated monolayer cells, cells incubated with sNP-Co or lyophilisate produced significantly more collagen type I (1.44-fold, $P=0.003$, and 1.36-fold, $P=0.002$, respectively) after 7 compared to 3 days, but significantly less $(1.77$-fold, $P=0.007)$ when rhIGF-1 was initially added. When comparing the different monolayer cell approaches at day 3, we found the highest collagen type I expression for cells incubated with lyophilisate, which was significantly higher compared to cells with sNP-Co (1.29-fold, $P=0.042)$ and rh-IGF-1 (1.42-fold, $P=0.009)$. Until day 7 , the amount of collagen type I increased for cells with lyophilisate, while it clearly dropped when cells were incubated with rh-IGF-1 instead. Cells loaded with control particles produced $15 \%$ more collagen type I than cells loaded with IGF-1-coupled nanoparticles (Figure 6B). On the collagen scaffold, cells loaded with sNP-Co produced significantly more $(41 \%)$ collagen type I than rhIGF-1-incubated cells measured at day 3 (Figure 6E).

Regarding the chondroinductive capacity of the scaffold, the overall picture indicates a higher collagen type II production for cells grown on the collagen scaffold compared to those grown on plastic. Additionally, there was a significant reduction in collagen type II expression for monolayer cells (Figure 6C) after 7 days in comparison to 3 days when the cells were initially incubated with sNP-IGF-1 (1.86-fold, $P=0.001$ ), sNP-CO (1.57-fold), and lyophilisate (1.62-fold). In contrast, cells grown on the collagen scaffold (Figure 6F) produced significantly higher amounts of collagen type II when sNP-IGF-1 (1.53-fold, $P=0.02$ ) or lyophilisate (1.97fold, $P<0.001$ ) was added. When comparing the four different monolayer cell approaches at day 3 , it is noticeable that sNP-IGF-1-loaded cells have the highest amount of collagen type II (mean $120.79 \mu \mathrm{g} / \mathrm{mL}$ ), which is significantly higher than for sNP-Co- (mean: $70.98 \mu \mathrm{g} / \mathrm{mL}, P=0.003$ ), rhIGF-1(mean: $74.82 \mu \mathrm{g} / \mathrm{mL}, P=0.005$ ), and lyophilisate- (mean: $57.99 \mu \mathrm{g} / \mathrm{mL}, P=0.003)$ incubated cells. This result points to a drug-effectiveness period of less than 3 days and an early chondroinductive effect in monolayer culture. After 7 days, there was less collagen type II synthesized in all approaches except for rh-IGF-1-stimulated cells (Figure 6C).

For cells grown on collagen-based scaffolds (Figure 6D-F), the expression level of procollagen type II in cells incubated with IGF-1-coupled nanoparticles was the same as in cells treated with sNP-Co, rhIGF-1, or lyophilisate after 3 days. After 7 days, the lyophilisatetreated group (positive control) showed the highest amount of procollagen type II (mean: $168.77 \mu \mathrm{g} / \mathrm{mL}$ ), which was significantly increased in comparison to the other 3 groups and those with lyophilisate. Cells incubated with sNP-IGF-1 had the second highest total quantity of procollagen type II in the supernatant (mean: $124.74 \mu \mathrm{g} / \mathrm{mL}$ ) after 7 days. In contrast to cells grown in a monolayer, we identified a comparable level of procollagen type II at 3 days for all four groups, pointing to the positive influence of collagen 
A
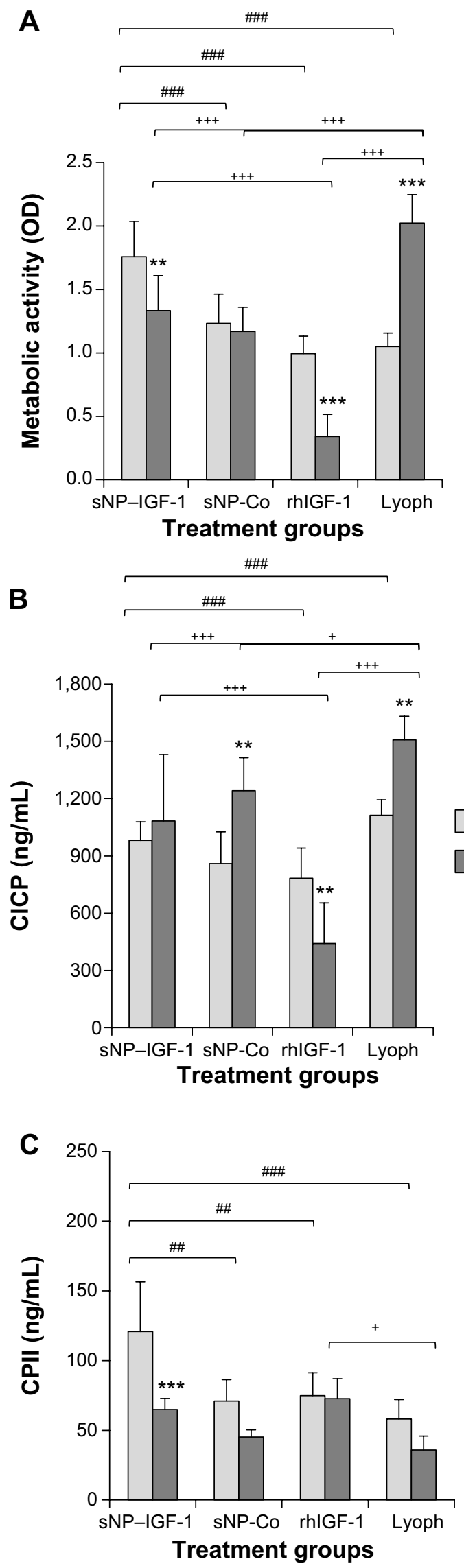

D

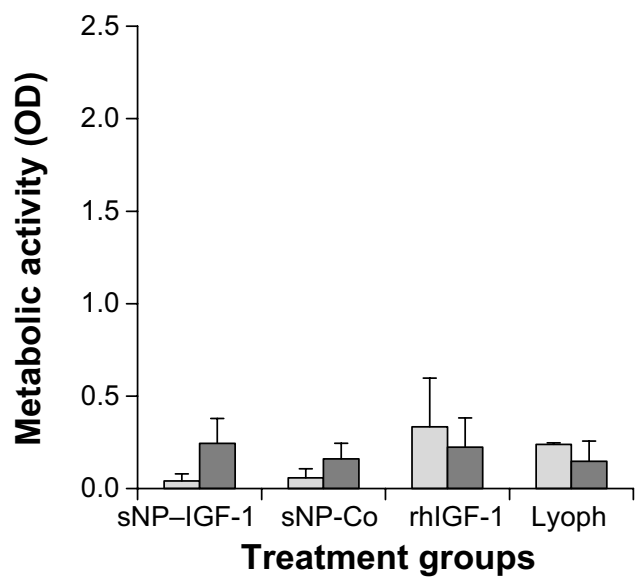

E
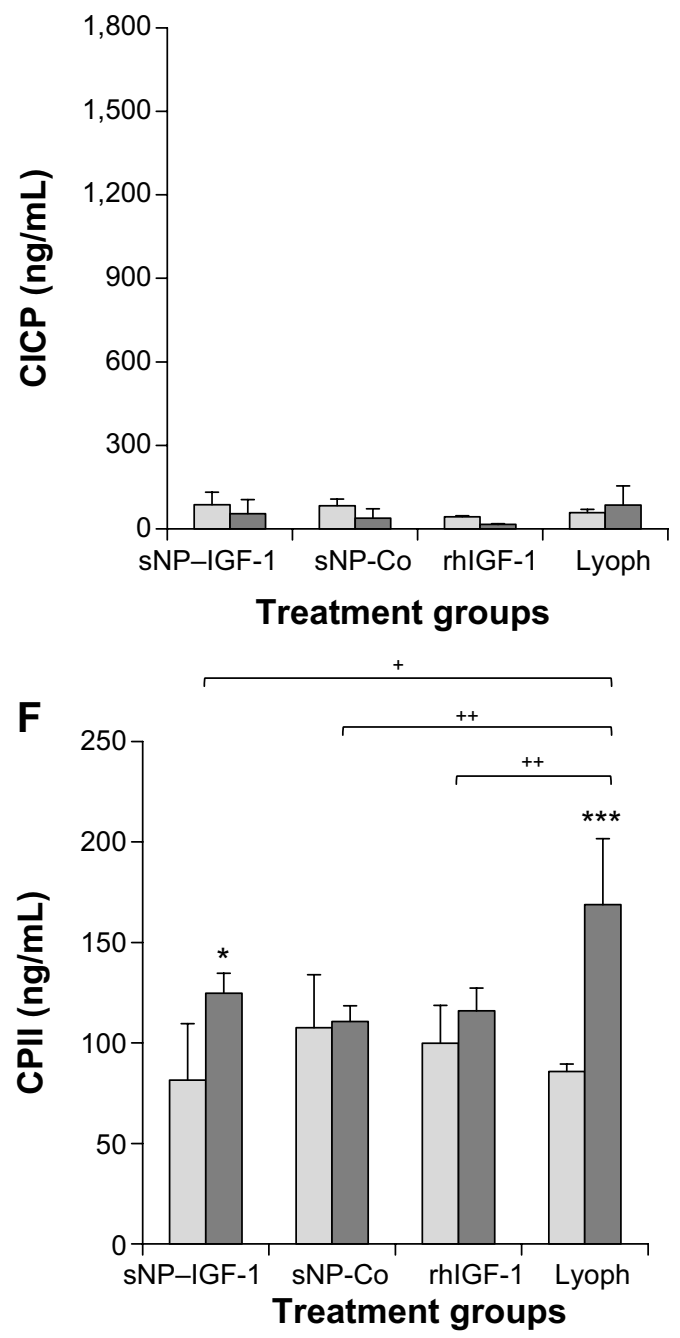

Figure 6 (Continued) 

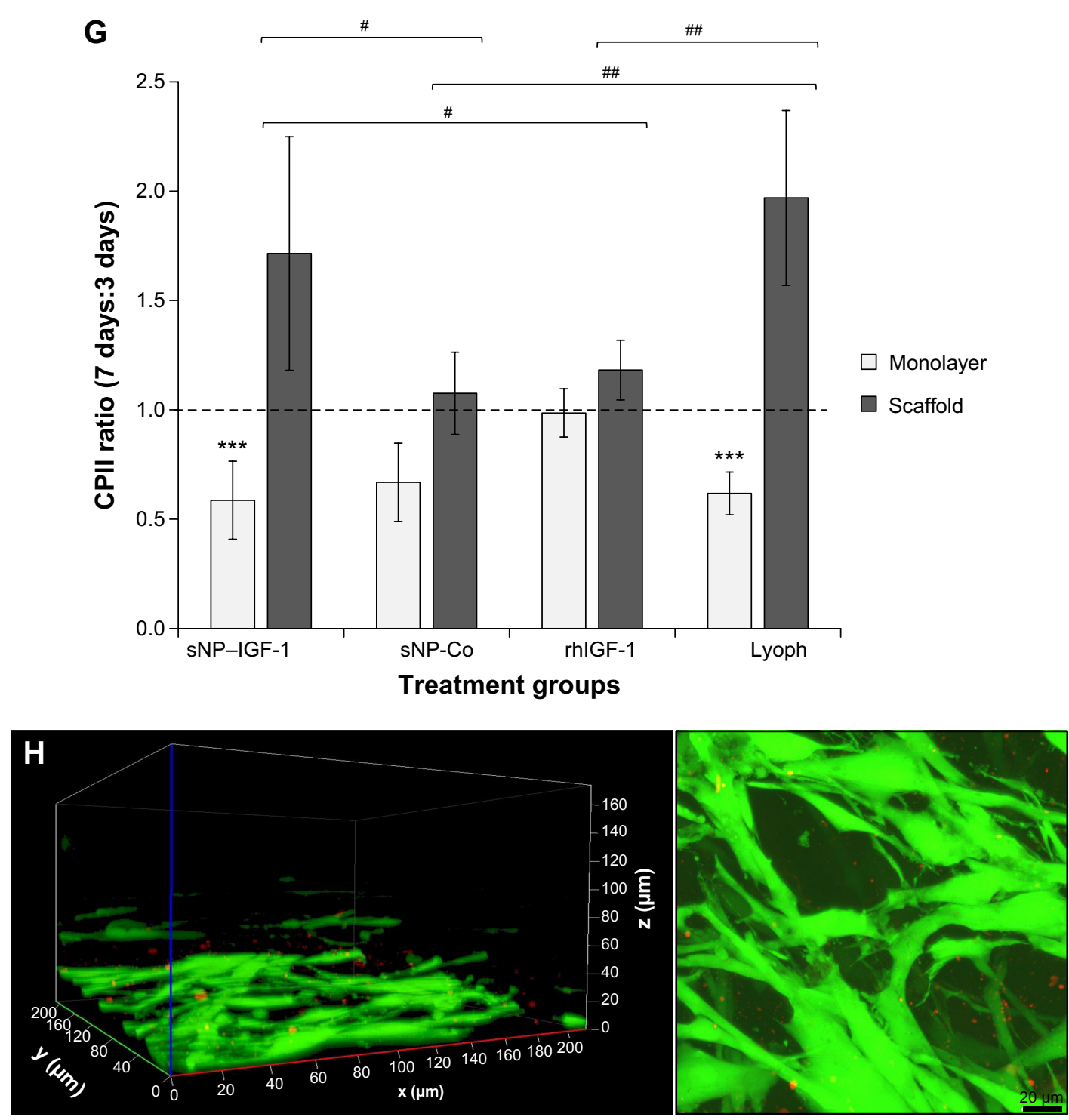

Figure 6 Collagen scaffolds enriched with IGF-I-coupled nanoparticles and growth factor lyophilisate have a positive impact on early chondrogenic redifferentiation. Notes: Chondrocytes were isolated from hyaline cartilage of patients $(n \geq 3)$ undergoing primary total knee joint replacement and were either cultured on cell culture plastic (A-C) or on a collagen scaffold (D-F) at a concentration of $1 \times 10^{5}$ cells $/ \mathrm{I} \mathrm{cm}^{2}$ each. Initially, culture medium was supplemented with rhIGF-I-coupled nanoparticles (sNPIGF-I; $12.5 \mu \mathrm{g} / \mathrm{mL}$ particle suspension $=50 \mathrm{ng} / \mathrm{mL}$ rhIGF-I), control particles (sNP-Co; $12.5 \mu \mathrm{g} / \mathrm{mL}$ particle suspension $=50 \mathrm{ng} / \mathrm{mL} \mathrm{NH}{ }_{2}$ ), rhIGF-I ( $50 \mathrm{ng} / \mathrm{mL}$ ), and growth factor Lyoph. Medium change (without supplements) was conducted every 2-3 days. After 3 and 7 days of cultivation, metabolic cell activity was determined with WST-I assay, and $\mathrm{CICP}$ (osteogenic marker) as well as CPII (chondrogenic marker) were quantified in the cell supernatant by means of enzyme-linked immunosorbent assay. Means and standard deviations are demonstrated. For statistically significance analyses, the post hoc-LSD ANOVA was applied (7 days compared to 3 days: $* P<0.05$, $* * P<0.0$ I, $* * * P<0.00$ I; groups compared at 3 days: ${ }^{\#} P<0.0$ I, ${ }^{\#} P<0.00$ I; groups compared at 7 days: ${ }^{+} P<0.05,+{ }^{+} P<0.0$ I, $\left.{ }^{++} P<0.00 \mathrm{I}\right)$. (G) Calculation of the ratio (7 days:3 days) of procollagen type II production by cells grown on scaffolds or on plastic with sNP-IGF-I, sNP-Co, rhIGF-I, and Lyoph. The post hoc-LSD ANOVA was applied (comparison of groups: ${ }^{P}<0.05$, $\# P<0.01$; scaffold compared to monolayer: $* * * P<0.00 I$ ). (H) Cells grown on the collagen scaffold enriched with sNP-IGF-I were stained with calcein-AM after 7 days (viable cells: fluoresce green; nanoparticles fluoresce: red). The left diagram shows a z-stack and the right picture shows a representative microscopic top view.

Abbreviations: ANOVA, analysis of variance; calcein-AM, calcein-acetoxymethyl; CICP, procollagen type I; CPII, procollagen type II; Lyoph, lyophilisate; LSD, least significant difference; OD, optical density; sNP, silica nanoparticles; sNP-Co, control nanoparticles; WST-I, water-soluble-tetrazolium salt; IGF-I, insulin-like growth factor I; rhIGF-I, recombinant human IGF-I.

scaffolds on the initiation of chondrogenic differentiation (independently of other stimulating factors). The collagen type II ratio ( 7 days: 3 days) indicated that the collagen synthesis rate was highest for cells grown on collagen-based scaffolds enriched with IGF-1-coupled nanoparticles (ratio 1.71:1) and lyophilisate (ratio 1.97:1) (Figure 6G). We found significant differences between sNP-IGF-1-treated cells grown on scaffolds compared to those incubated with control particles (negative control, $P=0.018$ ) and rhIGF-1 (conventional treatment, $P=0.044$ ). Moreover, sNP-IGF-1-treated cells as well as lyophilisate-treated cells had significantly higher collagen type II ratios $(P<0.001)$ when grown on scaffolds compared to those grown in a monolayer. Figure $6 \mathrm{H}$ confirms that the applied nanoparticles persisted within 
the scaffold over the cultivation period of 7 days and were bound by the cells.

\section{Discussion}

The collagen-based scaffold tested in this study was analyzed regarding its stability, biodegradability, and chondroinductive capacity. It was shown that the scaffold is stable during cultivation $\left(37^{\circ} \mathrm{C}, 5 \% \mathrm{CO}_{2}\right)$ in DMEM with different supplements over 14 days. Primary chondrocytes isolated from hyaline cartilage were initially expanded in the monolayer over two passages. It is known that during expansion in a monolayer culture, chondrocytes dedifferentiate and cease their cartilage-specific gene expression. ${ }^{31,32}$ Dedifferentiated cells are comparable with prechondrocytes found in immature cartilage. An advantage for tissue engineering is that those cells are still able to proliferate and infiltrate a scaffold designed for cartilage repair. By adding growth factors to the scaffold, maturation of the cartilage might be induced, resulting in cartilage regeneration. ${ }^{33}$ In our study, dedifferentiated cells cultured over 14 days infiltrated the collagen-based scaffold to a level of up to $120 \mu \mathrm{m}$. With the addition of the growth factor IGF-1, we aimed to induce or increase the chondrogenic differentiation, as IGF-1 had been shown to stimulate the adhesion of chondrocytes to extracellular matrix proteins like collagens and stimulate the proliferation of prechondrocytes. ${ }^{9,34}$ IGF-1 is important for the maintenance of cartilage integrity and matrix synthesis, but an overexpression of IGF-1 can induce hypertrophic differentiation and mineralization. ${ }^{35,36}$ Thus, a controlled delivery of biomolecules during the regenerative process is important to avoid adverse effects. Growth factors, in particular IGF-1, have a short half-life; therefore, it is desirable to administer them locally rather than systemically. ${ }^{37}$ It was shown that the addition of heparin-binding domains to IGF-1 led to an improved local and sustained delivery of IGF-1 to cartilage tissue. ${ }^{38}$ Nanoparticles coupled with growth factors are used as carriers for a controlled and longterm local stimulation of cells in medical applications. ${ }^{39}$ An improved strategy for retaining IGF-1 in articular cartilage defects would be the use of a chondroinductive scaffold enriched with growth factor-coupled nanoparticles. In this study, we used IGF-1-coupled sNP to stimulate dedifferentiated chondrocytes, directly in a monolayer or in combination with a collagen scaffold. We were able to detect the particles both in the monolayer and in the collagen-based scaffold (up to 14 days of cultivation), meaning that those particles are bound by the cells and also persist within the scaffold so that a sustained stimulation can be assumed. In previous in vitro studies, a dose-dependent cytotoxic effect of sNP was shown when concentrations of about 25-200 $\mu \mathrm{g}$ / $\mathrm{mL}$ were tested in human skin epithelial and lung epithelial cells, ${ }^{40}$ human embryonic kidney cells, ${ }^{41}$ and human endothelial cells. ${ }^{42}$ For our experiments, we used a particle concentration of $12.5 \mu \mathrm{g} / \mathrm{mL}$ and found no negative impact on cell vitality and proliferation of human dedifferentiated chondrocytes. Not only the concentration but also the size of nanoparticles plays a critical role regarding cytotoxicity. It was demonstrated that cytotoxic effects increased with a reduction in particle size. A particle size of 20-50 $\mathrm{nm}$ resulted in the highest cytotoxicity levels. ${ }^{41-43}$ Here, we used sNP with a diameter of $1 \mu \mathrm{m}$, which appeared to have no harmful effect on human chondrocytes.

The chondroinductive effect of nanoparticles coupled with IGF-1 resulted in a positive impact on collagen type II production within the first 2 days. However, in general, there were no differences between sNP-IGF-1, sNP-Co, and rhIGF-1 regarding the amount of collagen types I and II. For all, the amount of collagen type I was reduced after 4 days compared to 2 days while the collagen type II synthesis remained stable. After 3 and 7 days of cultivation of dedifferentiated chondrocytes in serum containing DMEM there was a general increase in metabolic cell activity for cells grown in a monolayer than for cells grown on the collagen scaffold. As we were able to identify viable cells within the scaffold, the striking difference in metabolic cell activity compared to monolayer cells might be due to the fact that the inner cells here may not have been adequately covered in the 1-hour incubation period of the WST-1 substance. Interestingly, the metabolic activity of cells cultured in a monolayer was significantly increased when initially incubated with lyophilisate. We used this platelet growth factor lyophilisate containing IGF-1, TGF- $\beta 1$, VEGF, and basic FGF for a positive control, as chondrogenesis is regulated by several growth factors which cause a synergistic effect. ${ }^{44}$ We could demonstrate that chondrogenic-stimulated cells in monolayer cultures produced much higher amounts of collagen type I than cells grown on the collagen-based scaffold. Simultaneously, we found increased collagen type II production for cells grown on the collagen scaffold compared to cells grown in a monolayer. These results fit with data from previous studies and confirm that a collagen-based scaffold supports chondrogenic properties. ${ }^{45}$ Furthermore, cells grown on the scaffold synthesized significantly more collagen type II when sNP-IGF-1 or lyophilisate was added, which indicates that the regeneration process in clinical applications can be optimized by combining the three basic approaches 
to tissue engineering: 1) the application of isolated cells or cell substitutes; 2 ) the delivery of stimulating growth factors; and 3) implanting a three-dimensional scaffold enriched with autologous cells. ${ }^{46}$

In summary, in the present in vitro study, a biocompatible collagen-based scaffold was infiltrated by dedifferentiated cells isolated from human articular cartilage and enriched with IGF-1-coupled sNP to positively influence the regenerative capacity. Cell viability was not compromised by the addition of sNP. However, the production of the cartilaginous matrix was increased by coupling of the growth factor IGF-1 to nanoparticles.

\section{Acknowledgments}

The authors gratefully thank the Ministry of Economic Affairs, Employment and Tourism of MecklenburgVorpommern, Germany and the European Union for financial support within the research project "SYNTERO". We thank Mr Friedrich-Karl Evert (mbp GmbH) and Dr Cornelia Prinz (DOT) for providing collagen scaffolds and growth factor lyophilisate, respectively. We wish to thank the Electron Microscopy Centre and the BMFZ of the University Medicine Rostock for enabling scanning electron and confocal scanning microscopy, respectively. We also thank Mrs Doris Hansmann for technical support.

\section{Author contributions}

All of the authors contributed substantially to the concept and design of the study, the drafting of the article, and the critical revision of the manuscript for important intellectual content. All of the authors have read and approved the final version of the manuscript for publication.

\section{Disclosure}

The authors report no conflicts of interest in this work.

\section{References}

1. Hunziker EB. Articular cartilage repair: basic science and clinical progress. A review of the current status and prospects. Osteoarthritis Cartilage. 2002;10(6):432-463.

2. Johnstone B, Alini M, Cucchiarini M, et al. Tissue engineering for articular cartilage repair - the state of the art. Eur Cell Mater. 2013;25: 248-267.

3. Musumeci G, Castrogiovanni P, Leonardi R, et al. New perspectives for articular cartilage repair treatment through tissue engineering: A contemporary review. World J Orthop. 2014;5(2):80-88.

4. Jonitz A, Lochner K, Tischer T, Hansmann D, Bader R. TGF- $\beta 1$ and IGF-1 influence the re-differentiation capacity of human chondrocytes in $3 \mathrm{D}$ pellet cultures in relation to different oxygen concentrations. Int $\mathrm{J} \mathrm{Mol}$ Med. 2012;30(3):666-672.

5. Davies LC, Blain EJ, Gilbert SJ, Caterson B, Duance VC. The potential of IGF-1 and TGFbeta 1 for promoting "adult" articular cartilage repair: an in vitro study. Tissue Eng Part A. 2008;14(7):1251-1261.
6. Abukawa H, Oriel BS, Leaf J, et al. Growth factor directed chondrogenic differentiation of porcine bone marrow-derived progenitor cells. J Craniofac Surg. 2013;24(3):1026-1030.

7. Tyler JA. Insulin-like growth factor 1 can decrease degradation and promote synthesis of proteoglycan in cartilage exposed to cytokines. Biochem J. 1989;260(2):543-548.

8. Loeser RF, Shanker G. Autocrine stimulation by insulin-like growth factor 1 and insulin-like growth factor 2 mediates chondrocyte survival in vitro. Arthritis Rheum. 2000;43(7):1552-1559.

9. Loeser RF. Growth factor regulation of chondrocyte integrins. Differential effects of insulin-like growth factor 1 and transforming growth factor beta on alpha 1 beta 1 integrin expression and chondrocyte adhesion to type VI collagen. Arthritis Rheum. 1997;40(2):270-276.

10. Lam J, Lu S, Kasper FK, Mikos AG. Strategies for Controlled delivery of biologics for cartilage repair. Adv Drug Deliv Rev. Epub 2014 Jun 30 .

11. Santo VE, Gomes ME, Mano JF, Reis RL. Controlled release strategies for bone, cartilage, and osteochondral engineering - Part I: recapitulation of native tissue healing and variables for the design of delivery systems. Tissue Eng Part B Rev. 2013;19(4):308-326.

12. Tarn D, Ashley CE, Xue M, Carnes EC, Zink JI, Brinker CJ. Mesoporous silica nanoparticle nanocarriers: biofunctionality and biocompatibility. Acc Chem Res. 2013;46(3):792-801.

13. Flad T, Schiestel T, Brunner H, et al. Development of an MHC-class I peptide selection assay combining nanoparticle technology and matrixassisted laser desorption/ionisation mass spectrometry. $J$ Immunol Methods. 2003;283(1-2):205-213.

14. Bian L, Zhai DY, Tous E, Rai R, Mauck RL, Burdick JA. Enhanced MSC chondrogenesis following delivery of TGF- $\beta 3$ from alginate microspheres within hyaluronic acid hydrogels in vitro and in vivo. Biomaterials. 2011;32(27):6425-6434.

15. Dausse Y, Grossin L, Miralles G, et al. Cartilage repair using new polysaccharidic biomaterials: macroscopic, histological and biochemical approaches in a rat model of cartilage defect. Osteoarthritis Cartilage. 2003; 11(1):16-28.

16. Simson JA, Strehin IA, Lu Q, Uy MO, Elisseeff JH. An adhesive bone marrow scaffold and bone morphogenetic-2 protein carrier for cartilage tissue engineering. Biomacromolecules. 2013;14(3):637-643.

17. Spiller KL, Liu Y, Holloway JL, et al. A novel method for the direct fabrication of growth factor-loaded microspheres within porous nondegradable hydrogels: controlled release for cartilage tissue engineering. J Control Release. 2012;157(1):39-45.

18. Olson A, Graver A, Grande D. Scaffolds for articular cartilage repair. J Long Term Eff Med Implants. 2012;22(3):219-227.

19. Brittberg M, Lindahl A, Nilsson A, Ohlsson C, Isaksson O, Peterson L. Treatment of deep cartilage defects in the knee with autologous chondrocyte transplantation. N Engl J Med. 1994;331(14):889-895.

20. Brittberg M, Peterson L, Sjögren-Jansson E, Tallheden T, Lindahl A. Articular cartilage engineering with autologous chondrocyte transplantation. A review of recent developments. J Bone Joint Surg Am. 2003;85-A Suppl 3:109-115.

21. Rastogi A, Srivastava P, Iqbal Z, Kumaraswamy V, Singh RP. Role of autologous chondrocyte transplantation in articular cartilage defects: An experimental study. Indian J Orthop. 2013;47(2):129-134.

22. Kon E, Filardo G, Di Matteo B, Perdisa F, Marcacci M. Matrix assisted autologous chondrocyte transplantation for cartilage treatment: A systematic review. Bone Joint Res. 2013;2(2):18-25.

23. Figueroa D, Espinosa M, Calvo R, et al. [Treatment of acute fullthickness chondral defects with high molecular weight hyaluronic acid; an experimental model]. Rev Esp Cir Ortop Traumatol. 2014;58(5): 261-266. Spanish.

24. Salzmann GM, Sauerschnig M, Berninger MT, et al. The dependence of autologous chondrocyte transplantation on varying cellular passage, yield and culture duration. Biomaterials. 2011;32(25):5810-5818.

25. Levingstone TJ, Matsiko A, Dickson GR, O’Brien FJ, Gleeson JP. A biomimetic multi-layered collagen-based scaffold for osteochondral repair. Acta Biomater. 2014;10(5):1996-2004. 
26. Berninger MT, Wexel G, Rummeny EJ, et al. Matrix-assisted autologous chondrocyte transplantation for remodeling and repair of chondral defects in a rabbit model. J Vis Exp. 2013;(75):e4422.

27. Lu T, Li Y, Chen T. Techniques for fabrication and construction of three-dimensional scaffolds for tissue engineering. Int J Nanomedicine. 2013;8:337-350

28. Smith LA, Liu X, Ma PX. Tissue Engineering with Nano-Fibrous Scaffolds. Soft Matter. 2008;4(11):2144-2149.

29. Grüttner C, Rudershausen S, Teller J, Westphal F, inventors; micromod Partikeltechnologie $\mathrm{GmbH}$, applicant. Process for the preparation of coloured and fluorescent polysilicic acid particles. Patent EP1036763B1. 2001 Dec 5.

30. Grüttner C, Müller K, Teller J, Westphal F. Synthesis and functionalisation of magnetic nanoparticles for hyperthermia applications. Int J Hyperthermia. 2013;29(8):777-789.

31. Schnabel M, Marlovits S, Eckhoff G, et al. Dedifferentiation-associated changes in morphology and gene expression in primary human articular chondrocytes in cell culture. Osteoarthritis Cartilage. 2002; 10(1):62-70.

32. Benz K, Breit S, Lukoschek M, Mau H, Richter W. Molecular analysis of expansion, differentiation, and growth factor treatment of human chondrocytes identifies differentiation markers and growth-related genes. Biochem Biophys Res Commun. 2002;293(1):284-292.

33. Khan IM, Francis L, Theobald PS, et al. In vitro growth factor-induced bio engineering of mature articular cartilage. Biomaterials. 2013;34(5): 1478-1487.

34. Chen Y, Ke J, Long X, et al. Insulin-like growth factor-1 boosts the developing process of condylar hyperplasia by stimulating chondrocytes proliferation. Osteoarthritis Cartilage. 2012;20(4):279-287.

35. Blumenfeld I, Livne E. The role of transforming growth factor (TGF)-beta, insulin-like growth factor (IGF)-1, and interleukin (IL)-1 in osteoarthritis and aging of joints. Exp Gerontol. 1999;34(7): $821-829$.
36. Ochiai H, Okada S, Saito A, et al. Inhibition of insulin-like growth factor-1 (IGF-1) expression by prolonged transforming growth factor- $\beta 1$ (TGF- $\beta 1$ ) administration suppresses osteoblast differentiation. $J$ Biol Chem. 2012;287(27):22654-22661.

37. Fuchs TF, Surke C, Stange R, et al. Local delivery of growth factors using coated suture material. Scientific World Journal. 2012;2012:109216.

38. Miller RE, Grodzinsky AJ, Vanderploeg EJ, et al. Effect of selfassembling peptide, chondrogenic factors, and bone marrow-derived stromal cells on osteochondral repair. Osteoarthritis Cartilage. 2010; 18(12):1608-1619.

39. Svenson $\mathrm{S}$. What nanomedicine in the clinic right now really forms nanoparticles? Wiley Interdiscip Rev Nanomed Nanobiotechnol. 2014;6(2): $125-135$.

40. Ahamed M. Silica nanoparticles-induced cytotoxicity, oxidative stress and apoptosis in cultured A431 and A549 cells. Hum Exp Toxicol. 2013;32(2): 186-195.

41. Wang F, Gao F, Lan M, Yuan H, Huang Y, Liu J. Oxidative stress contributes to silica nanoparticle-induced cytotoxicity in human embryonic kidney cells. Toxicol In Vitro. 2009;23(5):808-815.

42. Napierska D, Thomassen LC, Rabolli V, et al. Size-dependent cytotoxicity of monodisperse silica nanoparticles in human endothelial cells. Small. 2009;5(7):846-853.

43. Nabeshi H, Yoshikawa T, Matsuyama K, et al. Size-dependent cytotoxic effects of amorphous silica nanoparticles on Langerhans cells. Pharmazie. 2010;65(3):199-201.

44. Indrawattana $\mathrm{N}$, Chen $\mathrm{G}$, Tadokoro $\mathrm{M}$, et al. Growth factor combination for chondrogenic induction from human mesenchymal stem cell. Biochem Biophys Res Commun. 2004;320(3):914-919.

45. Chen JL, Duan L, Zhu W, Xiong J, Wang D. Extracellular matrix production in vitro in cartilage tissue engineering. J Transl Med. 2014; $12: 88$.

46. Langer R, Vacanti JP. Tissue engineering. Science. 1993;260(5110): 920-926.
International Journal of Nanomedicine

\section{Publish your work in this journal}

The International Journal of Nanomedicine is an international, peerreviewed journal focusing on the application of nanotechnology in diagnostics, therapeutics, and drug delivery systems throughou the biomedical field. This journal is indexed on PubMed Central, MedLine, CAS, SciSearch $\AA$, Current Contents $₫ /$ Clinical Medicine,

\section{Dovepress}

Journal Citation Reports/Science Edition, EMBase, Scopus and the Elsevier Bibliographic databases. The manuscript management system is completely online and includes a very quick and fair peer-review system, which is all easy to use. Visit http://www.dovepress.com/ testimonials.php to read real quotes from published authors. 